\title{
The Cutthroat Competition Between Termination and Transfer to Shape the Kinetics of Radical Polymerization
}

\author{
Gregory B. Smith, Gregory T. Russell \\ Department of Chemistry, University of Canterbury, Private Bag 4800, \\ Christchurch, New Zealand \\ Fax: (+64) 03 3642110; E-mail: greg.russell@canterbury.ac.nz
}

Summary: There is a fascinating interplay between termination and transfer that shapes the kinetics of radical polymerization (RP). In one limit all dead-chain formation is by termination, in the other by transfer. Because of chain-lengthdependent termination (CLDT), the rate law for RP takes a different form in each limit. However, common behavior is observed if one instead considers how the average termination rate coefficient varies with average degree of polymerization. Examples are given of using these principles to understand trends in actual RP data, and it is also demonstrated how to extract quantitative information on CLDT from simple steady-state experiments.

Keywords: chain transfer; kinetics (polym.); radical polymerization; termination

\section{Some Introductory Thoughts}

The steady-state rate of radical polymerization (RP) is given by

$$
\frac{-\mathrm{d} c_{\mathrm{M}}}{\mathrm{d} t}=k_{\mathrm{p}} c_{\mathrm{M}}\left(\frac{R_{\mathrm{init}}}{2 k_{\mathrm{t}}}\right)^{0.5}
$$

Here $c_{\mathrm{M}}$ is monomer concentration, $t$ time, $k_{\mathrm{p}}$ propagation rate coefficient, $R_{\text {init }}$ rate of initiation, and $k_{\mathrm{t}}$ termination rate coefficient. Measurement of initiator decomposition rates, and thus specification of $R_{\text {init }}$, has never been a problem. However for much of the history of $\mathrm{RP}$, the disentangling of $k_{\mathrm{p}}$ and $k_{\mathrm{t}}$ was a problem. This was solved in 1987 when it was shown that by relatively simple analysis of the molecular weight distribution from a pulsed-laser polymerization (PLP), the value of $k_{\mathrm{p}}$ could be obtained without requirement for any

knowledge of $k_{\mathrm{t}}$ (or $R_{\text {init) }}{ }^{[1]}$ So enthusiastically and successfully was this method adopted by the RP community that within just a few years it was recommended by an IUPAC Working Party as the method of choice for $k_{\mathrm{p}}$ determination; ${ }^{[2]}$ recent reviews emphasize just how widely the method has been deployed. ${ }^{[3,4]}$ 
Table 1. Critical evaluation of methods for measuring $k_{\mathrm{t}}{ }^{[5]}$

\begin{tabular}{|c|c|c|c|c|}
\hline Method & $\begin{array}{l}\text { Conversion } \\
\text { dependence }\end{array}$ & $\begin{array}{l}\text { Chain-length } \\
\text { dependence }\end{array}$ & Instrumentation & Applicability \\
\hline Steady-state rate & Yes & $\mathrm{No}^{\mathrm{a})}$ & Simple & Wide \\
\hline $\begin{array}{l}\text { Steady-state } \\
\text { EPR }\end{array}$ & $\begin{array}{l}\text { Yes (not for low } \\
c_{\mathrm{R}}{ }^{\mathrm{b})} \text { ) }\end{array}$ & No & $\begin{array}{l}\text { Expensive, } \\
\text { requires } \\
\text { expertise }\end{array}$ & Wide \\
\hline Living RP & $\begin{array}{l}\text { No (may be } \\
\text { possible) }\end{array}$ & $\begin{array}{l}\text { Yes (usually for } \\
\text { small chain } \\
\text { lengths only) }\end{array}$ & Simple & Wide \\
\hline $\begin{array}{l}\text { Classical post- } \\
\text { effect (including } \\
\text { with EPR) }\end{array}$ & $\begin{array}{l}\text { Yes (difficult at } \\
\text { low conversion) }\end{array}$ & No & $\begin{array}{l}\text { Requires } \\
\text { expertise }\end{array}$ & Wide \\
\hline $\begin{array}{l}\text { Single-pulse } \\
\text { PLP }\end{array}$ & Yes & $\begin{array}{l}\text { Yes (long chain } \\
\text { lengths only) }\end{array}$ & $\begin{array}{l}\text { Expensive, } \\
\text { requires } \\
\text { expertise }\end{array}$ & Wide \\
\hline $\begin{array}{l}\text { EPR with } \\
\text { single-pulse } \\
\text { PLP }\end{array}$ & Yes & $\begin{array}{l}\text { Yes (if } k_{\mathrm{p}} \text { not } \\
\text { too high) }\end{array}$ & $\begin{array}{l}\text { Very expensive, } \\
\text { requires much } \\
\text { expertise }\end{array}$ & $\begin{array}{l}\text { Limited (low } \\
\text { and moderate } k_{\mathrm{t}} \\
\text { only) }\end{array}$ \\
\hline Rotating sector & $\begin{array}{l}\text { No (may be } \\
\text { possible) }\end{array}$ & $\begin{array}{l}\text { No (may be } \\
\text { possible) }\end{array}$ & $\begin{array}{l}\text { Sophisticated } \\
\text { analysis }\end{array}$ & Wide \\
\hline $\begin{array}{l}\text { Buback's } \\
\text { multiple-pulse } \\
\text { PLP }\end{array}$ & Yes & $\begin{array}{l}\text { No (may be } \\
\text { possible) }\end{array}$ & $\begin{array}{l}\text { Pulsed laser } \\
\text { required }\end{array}$ & Wide \\
\hline $\begin{array}{l}\text { Olaj's multiple- } \\
\text { pulse PLP }\end{array}$ & $\begin{array}{l}\text { No (may be } \\
\text { possible) }\end{array}$ & $\begin{array}{l}\text { Yes (long chain } \\
\text { lengths only) }\end{array}$ & $\begin{array}{l}\text { Pulsed laser } \\
\text { required }\end{array}$ & $\begin{array}{l}\text { Limited } \\
\left.\text { (requires } \rho^{b}\right)\end{array}$ \\
\hline $\begin{array}{l}\text { Time-resolved } \\
\text { quenching }\end{array}$ & No & No & Simple & $\begin{array}{l}\text { Limited (low } k_{\mathrm{p}} \\
\text { only) }\end{array}$ \\
\hline $\begin{array}{l}\left.D P_{\mathrm{w}} \mathrm{b}\right) \text { from } \\
\text { multiple-pulse } \\
\text { PLP }\end{array}$ & No & $\begin{array}{l}\text { Yes (long chain } \\
\text { lengths only) }\end{array}$ & Laser required & $\begin{array}{l}\text { Limited (no } \\
\text { transfer) }\end{array}$ \\
\hline $\begin{array}{l}\text { Low-frequency } \\
\text { PLP }\end{array}$ & No & $\begin{array}{l}\text { Yes (power-law } \\
\text { only) }\end{array}$ & $\begin{array}{l}\text { Laser required; } \\
\text { sophisticated } \\
\text { analysis }\end{array}$ & $\begin{array}{l}\text { Limited (no } \\
\text { transfer) }\end{array}$ \\
\hline
\end{tabular}


With the measurement of $R_{\text {init }}$ and $k_{\mathrm{p}}$ ticked off, that of the third and last fundamental rate parameter of $\mathrm{RP}, k_{\mathrm{t}}$, becomes easy: it follows simply from a measurement of rate. If the experiment is carried out in a steady state, then one uses Equation (1), involving $k_{\mathrm{p}}{ }^{2 / k_{\mathrm{t}}}$; if it is carried out in a non-steady state, then the rate will instead yield $k_{\mathrm{p}} / k_{\mathrm{t}}$, still enabling $k_{\mathrm{t}}$ to be easily obtained. ${ }^{[5,6]}$ This has opened up hope that many of the frustrations associated with $k_{\mathrm{t}}$, a centrally important parameter, will be resolved. With this in mind, an IUPAC Task-Group looking into this broad issue was created. A comprehensive analysis of the seemingly multitudinous methods for measuring $k_{\mathrm{t}}$ was carried out. ${ }^{[5]}$ A summary of the deliberations is presented in Table 1. Of course some methods were considered to be superior to others. Most notably, the single-pulse PLP method, as proposed, ${ }^{[7]}$ developed and widely exploited ${ }^{[4]}$ by Buback and coworkers, was felt to be peerless "because of its exceptional precision and because of the unparalleled control over conversion which it gives: it may routinely be used to measure $k_{\mathrm{t}}$ at conversion intervals of less than $1 \% .{ }^{,[5]}$ However it was also concluded that all the methods in Table 1 potentially should provide good $k_{\mathrm{t}}$ values, as long as the user is aware of particular limitations that apply (see Table 1). This finding came as something of a surprise, because the notorious problem of excessive scatter ${ }^{[6]}$ in literature values of $k_{\mathrm{t}}$ was commonly assumed to arise, at least in part, from some methods of measurement simply being inherently bad techniques. There is no doubt that scatter in literature data for $k_{\mathrm{t}}$ is due in no small part to naive employment of measurement methods, for example allowing a large change of conversion over the course of a $k_{\mathrm{t}}$ measurement, or the choice of a poor value of $k_{\mathrm{p}}$ or $R_{\text {init }}$ for data analysis. However it would also seem that theoretical forces have been at work. By far the most notable of these is chain-length-dependent termination (CLDT). ${ }^{[6]}$ The aim of the present work is to illuminate some of the most significant trends to which CLDT gives rise, and thus to reveal the rich impact that it has on $k_{\mathrm{t}}$. Once these effects are comprehended, it becomes clear why many purportedly identical $k_{\mathrm{t}}$ measurements in fact were nothing of the sort, thus explaining why different values of $k_{\mathrm{t}}$ were found.

\section{The Competition Between Termination and Transfer}

The standard reaction scheme for RP comprises of initiation, propagation, termination and 
chain transfer to (small-molecule) species X, whether monomer, solvent, chain-transfer agent (CTA) or initiator. The corresponding population balance equations are

$$
\begin{aligned}
& \frac{\mathrm{d} c_{\mathrm{R}^{1}}}{\mathrm{~d} t}=R_{\text {init }}+k_{\mathrm{trX}} c_{\mathrm{X}} c_{\mathrm{R}}-k_{\mathrm{p}} c_{\mathrm{M}} c_{\mathrm{R}^{1}}-k_{\mathrm{trX}} c_{\mathrm{X}} c_{\mathrm{R}^{1}}-2 c_{\mathrm{R}^{1}} \sum_{j=1}^{\infty} k_{\mathrm{t}}^{1, j} c_{\mathrm{R}^{j}} \\
& \frac{\mathrm{d} c_{\mathrm{R}^{i}}}{\mathrm{~d} t}=k_{\mathrm{p}} c_{\mathrm{M}} c_{\mathrm{R}^{i-1}}-k_{\mathrm{p}} c_{\mathrm{M}} c_{\mathrm{R}^{i}}-k_{\mathrm{trX}} c_{\mathrm{X}} c_{\mathrm{R}^{i}}-2 c_{\mathrm{R}^{i}} \sum_{j=1}^{\infty} k_{\mathrm{t}}^{i, j} c_{\mathrm{R}^{j}}, i=2, \infty \\
& \frac{\mathrm{d} c_{\mathrm{D}^{i}}}{\mathrm{~d} t}=2 \lambda c_{\mathrm{R}^{i}} \sum_{j=1}^{\infty} k_{\mathrm{t}}^{i, j} c_{\mathrm{R}^{j}}+k_{\mathrm{trX}} c_{\mathrm{X}} c_{\mathrm{R}^{i}}+(1-\lambda) \sum_{j=1}^{i-1} k_{\mathrm{t}}^{j, i-j} c_{\mathrm{R}^{j}} c_{\mathrm{R}^{i-j}}, i=1, \infty
\end{aligned}
$$

Hopefully the notation here is largely self-explanatory: $k$ always denotes a rate coefficient and $c$ a concentration; the subscript of a rate coefficient denotes the particular reaction - initiation, propagation, termination, and transfer to species $\underline{X}$; the subscript of a concentration signifies

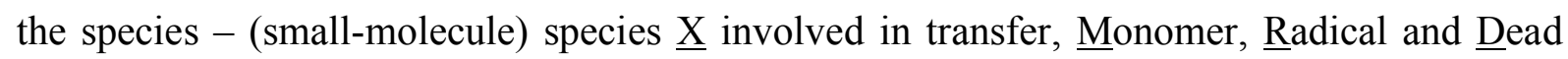
chain; lastly, a superscript always denotes chain length. Thus, for example, $c_{\mathrm{R}^{i}}$ signifies the concentration of radicals of degree of polymerization $i$, while $k_{\mathrm{t}}^{i, j}$ represents the rate coefficient for termination between radicals of chain length $i$ and $j$. The only exceptions to these principles of notation are that the rate of initiation is written directly as $R_{\text {init }}$ rather than in terms of rate coefficients and a concentration, and the fraction of termination events occurring by disproportionation, $\lambda$, is used rather than introducing rate coefficients for disproportionation and combination explicitly into Equation (4).

While Equations (2)-(4) may look complicated, in fact they are easily derived, as they consist merely of gain and loss terms resulting from the various reactions that produce and consume, respectively, each species. Further, it is sobering to realize that these equations only become even more forbidding if further RP reactions occur, for example chain transfer to polymer. They also become more complicated if additional reactions are deemed to be chain-length dependent, most notably propagation. ${ }^{[8]}$ However while this effect can be highly significant where the average degree of polymerization is less than $100,{ }^{[8]}$ it seems unlikely that it is relevant where genuine polymer is made. Thus it will not be considered in the present work, where a chain-length-independent value of $k_{\mathrm{p}}$ will always be used. This serves to focus attention wholly onto CLDT. This is as desired, because it is felt that this phenomenon is by far the most important driver of RP kinetics. 
For homo-termination rate coefficients, the following simple model will be used in all the calculations of this work:

$$
k_{\mathrm{t}}^{i, i}=k_{\mathrm{t}}^{1,1} i^{-e}
$$

Here $k_{\mathrm{t}}{ }^{1,1}$ is the rate coefficient for termination between monomeric radicals and $e$ is an exponent quantifying the strength of the CLDT: the larger the value of $e$, the stronger the variation with chain length. Although recent theoretical ${ }^{[9]}$ and experimental ${ }^{[10,11]}$ work has shown that this two-parameter model is an oversimplification of reality, it is a nice model to use for calculations, as it clearly exposes the general effects of CLDT on RP kinetics, ${ }^{[12-14]}$ and these trends are essentially the same for more complex homo-termination models. ${ }^{[9]}$ The same also holds for cross-termination models, ${ }^{[12-14]}$ and so the simplest one will be employed here unless otherwise stated:

$$
k_{\mathrm{t}}^{i, j}=\left(k_{\mathrm{t}}^{i, i} k_{\mathrm{t}}^{j, j}\right)^{0.5}=k_{\mathrm{t}}^{1,1}(i j)^{-e / 2}
$$

This is called the geometric mean model, and it is especially amenable to computational use. $^{[9,14,15]}$

Most radical polymerizations are carried out with continuous initiation, which means that to excellent approximation they are in a steady state. Thus the steady-state solutions of Equations (2) and (3) will be computed in this work. ${ }^{[16,17]}$ This procedure yields the full set of $c_{\mathrm{R}} i$ values, from which one may evaluate the overall rate coefficient for termination, $\left\langle k_{\mathrm{t}}\right\rangle$ :

$$
\left\langle k_{\mathrm{t}}\right\rangle=\sum_{i=1}^{\infty} \sum_{j=1}^{\infty} k_{\mathrm{t}}^{i, j} \frac{c_{\mathrm{R}^{i}{ }{ }_{\mathrm{R}^{j}}}}{c_{\mathrm{R}}{ }^{2}}
$$

Thus defined, $\left\langle k_{\mathrm{t}}\right\rangle$ replaces $k_{\mathrm{t}}$ in Equation (1), which otherwise remains an exact expression for steady-state rate. For this reason $\left\langle k_{\mathrm{t}}\right\rangle$ is a tremendously important quantity: its variations directly dictate, through Equation (1), variations in rate of polymerization. This is why CLDT can be said to shape RP kinetics.

To begin with we present in Figure 1 calculated results for the variation of (steady-state) $\left\langle k_{t}\right\rangle$ with (a) rate of initiation and (b) frequency of chain transfer. It is stressed that in these calculations the only quantities that are varied are $R_{\text {init }}$ (alone) in (a) and $k_{\operatorname{trX}} c_{\mathrm{X}}$ (alone) in (b). In other words, all values of $k_{\mathrm{t}}^{i, j}$ are identical in all the calculations for Figure 1, and yet, 
remarkably, there is large variation of $\left\langle k_{\mathrm{t}}\right\rangle$, the termination rate coefficient that would be measured experimentally. Further, the way in which $\left\langle k_{\mathrm{t}}\right\rangle$ varies with $R_{\text {init }}$ and with $k_{\operatorname{trX}} c_{\mathrm{X}}$ varies depending on the value of these quantities.
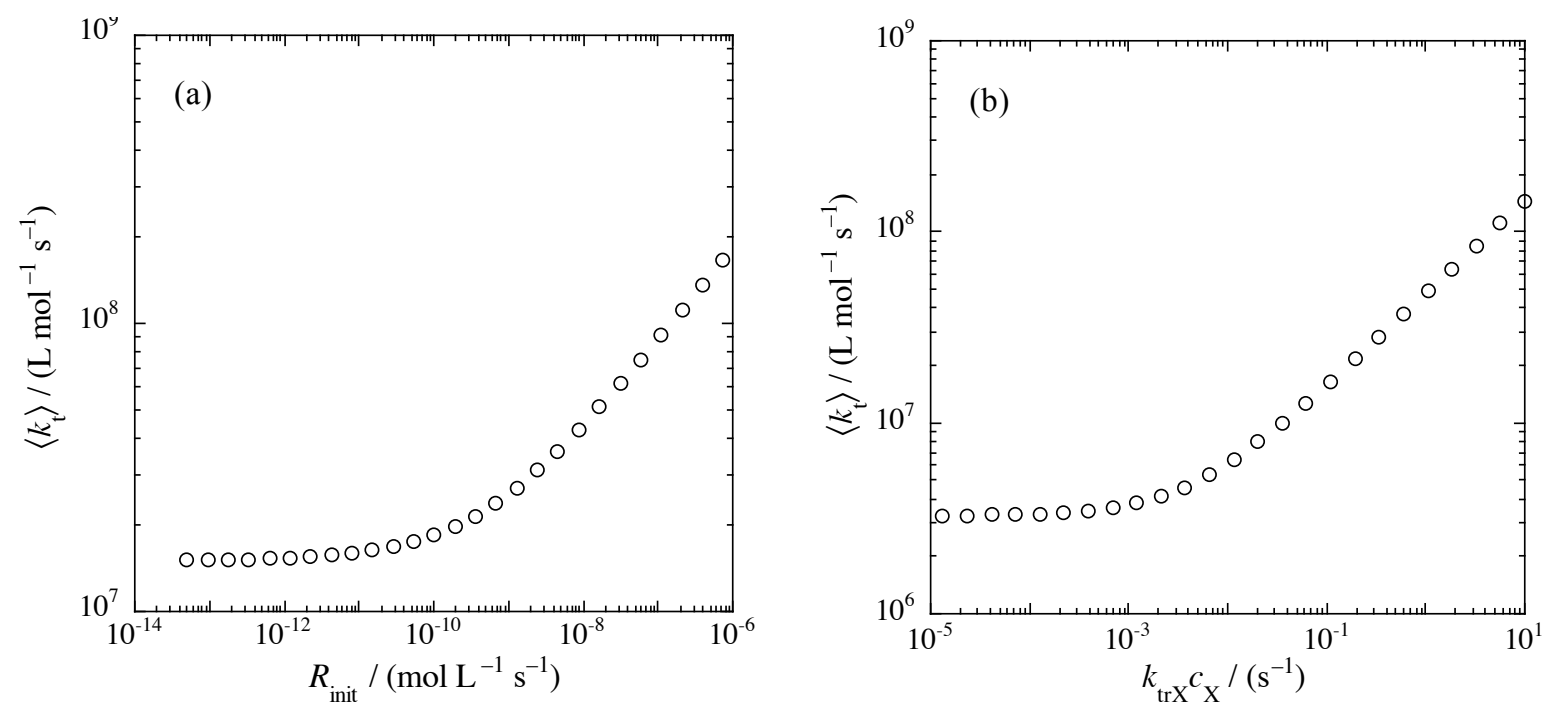

Figure 1. Calculated values of overall termination rate coefficient, $\left\langle k_{\mathrm{t}}\right\rangle$, using $k_{\mathrm{t}} 1,1=1 \times 10^{9}$ $\mathrm{L} \mathrm{mol}^{-1} \mathrm{~s}^{-1}, e=0.5$ and $k_{\mathrm{p}} c_{\mathrm{M}}=1000 \mathrm{~s}^{-1}$. (a) $k_{\mathrm{trX}} c_{\mathrm{X}}=0.1 \mathrm{~s}^{-1}$ with varying rate of initiation, $R_{\text {init. }}$ (b) $R_{\text {init }}=5 \times 10^{-12} \mathrm{~mol} \mathrm{~L}^{-1} \mathrm{~s}^{-1}$ with varying transfer frequency, $k_{\operatorname{trX}} c_{\mathrm{X}}$.

It turns out that what Figure 1 beautifully brings to light is a competition between termination and transfer to shape RP kinetics. First considering Figure 1(a), the easiest trend to understand is, perhaps counter-intuitively, the region at high $R_{\text {init }}$ where the change of $\left\langle k_{\mathrm{t}}\right\rangle$ is strongest, because this variation is due to a commonly realized effect of CLDT: as $R_{\text {init }}$ increases, the radical chain-length distribution (RCLD), i.e., the $c_{\mathrm{R}^{i}}$ distribution, becomes more weighted towards small chain lengths, and thus $\left\langle k_{\mathrm{t}}\right\rangle$ increases, because CLDT means that small radicals terminate relatively quickly. ${ }^{[18]}$ From how this argument has just been expressed there is no reason to expect that this trend should not continue down to low values of $R_{\text {init, }}$ so the puzzling result of Figure 1(a) is perhaps that $\left\langle k_{\mathrm{t}}\right\rangle$ becomes independent of $R_{\text {init }}$ at low $R_{\text {init }}$, even though CLDT is still very much operative (see what is written above about $k_{\mathrm{t}}{ }^{i, j}$ values). Why is this? The explanation is that at low values of $R_{\text {init }}$, radical creation is dominated by transfer rather than by initiation, i.e., $R_{\text {init }} \ll k_{\operatorname{trX}} c_{X} c_{R}$ in Equation (2). Thus dead-chain formation is predominantly by transfer and there is negligible variation in the RCLD as $R_{\text {init }}$ 
changes, which means that $\left\langle k_{\mathrm{t}}\right\rangle$ is independent of $R_{\text {init }}$ (see Equation (7)).

For obvious reasons we term the situation at low $R_{\text {init }}$ in Figure 1(a) the transfer limit. Physically it corresponds to a radical undergoing many, many cycles of growth and transfer before eventually undergoing termination, something that can occur at any chain length, i.e., termination does not necessarily happen at short chain length. With this grasped, we can now reach a deeper understanding of the converse situation at high $R_{\text {init: }}$ this the termination limit, in which $k_{\operatorname{trX}} c_{X} c_{\mathrm{R}}$ « $R_{\text {init }}$ in Equation (2), and thus there is variation of $c_{\mathrm{R}} i$ values as $R_{\text {init }}$ changes, meaning that there is variation of $\left\langle k_{t}\right\rangle$. Physically this limit corresponds to all deadchain formation being by termination, and thus every radical that is created undergoes just one generation of growth before experiencing its ultimate fate at the hands of termination. Figure (a) also reveals that at intermediate $R_{\text {init }}$ there is a transition between the two limits. Physically this is the region of relatively even competition between transfer and termination, i.e., there is significant dead-chain formation by both these pathways, something that is specifically reflected in the $\left\langle k_{\mathrm{t}}\right\rangle$ behavior: it is intermediate between those of the two limits.

Turning now to Figure 1(b), in it one sees all the same phenomena as in Figure 1(a), except that roles are now reversed. This is because it is $k_{\operatorname{trX}} c_{\mathrm{X}}$ rather than $R_{\text {init }}$ that is being varied. An increase in the transfer frequency means that the rate of production of small radicals is increased, meaning that the RCLD becomes more weighted towards small radicals, meaning that $\left\langle k_{\mathrm{t}}\right\rangle$ is increased. This explains the strong variation of $\left\langle k_{\mathrm{t}}\right\rangle$ that one observes at high $k_{\mathrm{trX}} c_{\mathrm{X}}$ in Figure 1(b). Because $k_{\operatorname{trX}} c_{\mathrm{R}}$ is high it means that $R_{\text {init }}$ " $k_{\operatorname{trX}} c_{X} c_{\mathrm{R}}$, i.e., one is in the transfer limit. Thus, paradoxically, it is now the transfer limit in which $\left\langle k_{\mathrm{t}}\right\rangle$ varies strongly. Conversely, at low $k_{\operatorname{trX}} c_{\mathrm{X}}$ one is in the termination limit, in which event $\left\langle k_{\mathrm{t}}\right\rangle$ is constant because $R_{\text {init }}$ is now constant: the variation of $k_{\operatorname{trX}} c_{\mathrm{X}}$ now has no effect on $\left\langle k_{\mathrm{t}}\right\rangle$, because termination dominates its competition with transfer. Finally, at intermediate $k_{\operatorname{trX}} c_{\mathrm{X}}$ this competition is relatively evenly balanced, and there is a transition between the two limiting behaviors.

This discussion of Figure 1 has been long because it reveals much fascinating, subtle behavior. It is felt with conviction that these patterns are highly relevant to the study of RP kinetics, because realistic parameter values and a general kinetic model have been used to generate these results. In other words, these calculations have not been specially designed to 
produce the trends on display; rather, any CLDT model combined with reasonable values of rate coefficients will produce results of the same form. Of course it is correct to point out that no set of experiments will have the 8-orders-of-magnitude variation of initiator concentration at first implied by Figure 1(a). However this is to ignore that one may easily change $R_{\text {init }}$ by this amount through choice of initiator. In other words, the point of Figure 1(a) is that in a set of experiments with a slowly decomposing initiator one will be at the low- $R_{\text {init }}$ end of Figure 1(a), where one will observe very different termination behavior to a set of experiments that is otherwise identical except for having a rapidly decomposing initiator. Analogous applies with Figure 1(b) and choice of CTA.

The remainder of this paper will look at some of the behaviors of Figure 1 in more detail, including giving examples of their expression in experimental data, thereby authenticating the point above that these considerations are highly relevant to understanding of RP kinetics, in fact it is contended that they are integral for this purpose.

\section{The Termination Limit}

Making the steady-state assumption and the long-chain approximation, use of Equations (5) and (6) in Equations (2), (3) and (7) for the case of $k_{\operatorname{trX}}=0$ (i.e., the termination limit) results in $^{[9,14,15]}$

$$
\left\langle k_{\mathrm{t}}\right\rangle=k_{\mathrm{t}}^{1,1}\left[\Gamma\left(\frac{2}{2-e}\right)\right]^{-2}\left[\frac{\left(2 R_{\mathrm{init}} k_{\mathrm{t}}^{1,1}\right)^{0.5}}{k_{\mathrm{p}} c_{\mathrm{M}}}\left(\frac{2}{2-e}\right)\right]^{2 e /(2-e)}
$$

This equation holds strictly only for the geometric mean model, the physical basis of which is dubious for RP. ${ }^{[14]}$ However, the remarkable thing about Equation (8) is that it holds qualitatively and semi-quantitatively for all models of cross-termination. ${ }^{[12,13]}$ This is exemplified in Figure 2, which also shows results ${ }^{[14,19]}$ for the diffusion and harmonic mean models, Equations (9) and (10) respectively, both of which are physically plausible for RP:

$$
\begin{aligned}
& k_{\mathrm{t}}^{i, j}=\frac{1}{2}\left(k_{\mathrm{t}}^{i, i}+k_{\mathrm{t}}^{j, j}\right)=\frac{1}{2} k_{\mathrm{t}}^{1,1}\left(i^{-e}+j^{-e}\right) \\
& k_{\mathrm{t}}^{i, j}=k_{\mathrm{t}}^{1,1}\left(\frac{2 i j}{i+j}\right)^{-e}
\end{aligned}
$$



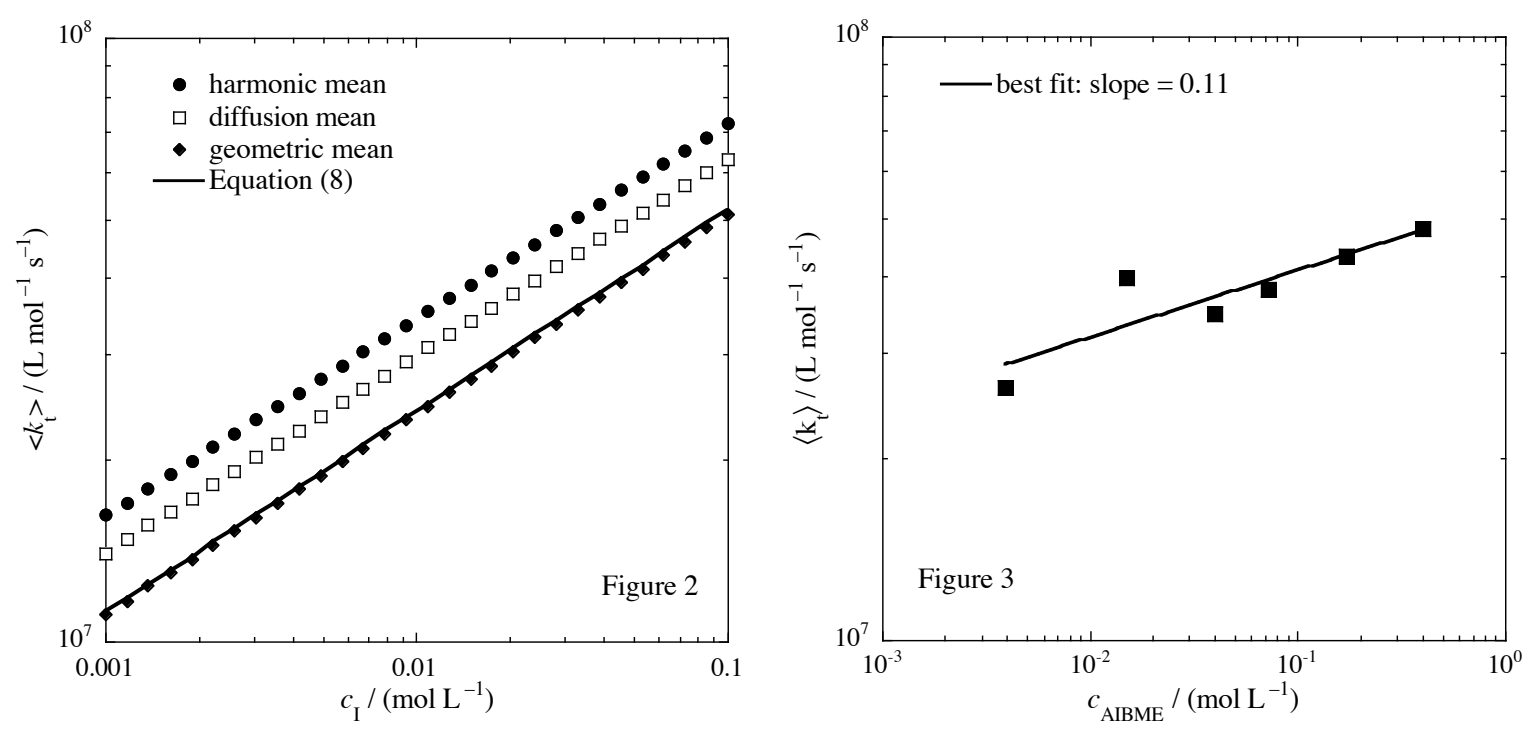

Figure 2 (left). Computed ${ }^{[14,19]}$ variation of overall termination rate coefficient, $\left\langle k_{\mathrm{t}}\right\rangle$, with initiator concentration, $c_{\mathrm{I}}$, for three different cross-termination models, as indicated. Also shown are values calculated with Equation (8). Parameter values employed: $k_{\mathrm{t}}{ }^{1,1}=1 \times 10^{9}$ $\mathrm{L} \mathrm{mol}^{-1} \mathrm{~s}^{-1}, e=0.5, R_{\text {init }}=c_{\mathrm{I}} \times 2 \times 10^{-7} \mathrm{~s}^{-1}, k_{\mathrm{p}} c_{\mathrm{M}}=1000 \mathrm{~s}^{-1}, k_{\mathrm{trX}}=0$.

Figure 3 (right). Variation of overall termination rate coefficient, $\left\langle k_{\mathrm{t}}\right\rangle$, with concentration of 2,2'-azoisobutyromethylester (AIBME), $c_{\text {AIBME }}$, for bulk RP of MMA at $40{ }^{\circ} \mathrm{C}^{[19,20]}$ The $\left\langle k_{t}\right\rangle$ measurements were made using the "steady-state rate" method of Table 1.

Because of the model independence of Equation (8) (providing $e$ is not too large ${ }^{[14,19]}$ ), one may use it to analyze data from experiments in which there is negligible dead-chain formation by transfer, regardless of the mechanism of cross-termination that actually holds (i.e., one does not even need to know how cross-termination occurs). For example, Equation (8) describes quantitatively the variation of $\left\langle k_{t}\right\rangle$ with $c_{M}$ (i.e., changing solvent concentration) and $k_{\mathrm{t}}^{1,1}$ (i.e., changing solvent viscosity). Here we will illustrate the utility of Equation (8) by applying it to a set of experiments for which only initiator concentration, $c_{\mathrm{I}}$, was varied. The data is from low-conversion bulk polymerization of methyl methacrylate (MMA) ${ }^{[20]}$ and is presented in Figure 3. Equation (8) stipulates that

$$
\begin{aligned}
& \text { slope of } \log \left\langle k_{\mathrm{t}}\right\rangle v \mathrm{~s} . \log c_{\mathrm{I}}=\frac{e}{(2-e)} \\
& \text { intercept of } \log \left\langle k_{\mathrm{t}}\right\rangle v \text { s. } \log c_{\mathrm{I}} \approx \log \left\{k_{\mathrm{t}}^{1,1}\left[\Gamma\left(\frac{2}{2-e}\right)\right]^{-2}\left[\frac{\left(4 f k_{\mathrm{d}} k_{\mathrm{t}}^{1,1}\right)^{0.5}}{k_{\mathrm{p}} c_{\mathrm{M}}} \frac{2}{2-e}\right]^{2 e /(2-e)}\right\}
\end{aligned}
$$


The new quantities here are initiator efficiency $f$ and initiator decomposition rate coefficient $k_{\mathrm{d}}$, i.e., $R_{\text {init }}=2 f k_{\mathrm{d}} c_{\mathrm{I}}$. Firstly applying Equation (11) to the best-fit line of the data of Figure 3, one obtains $e=0.20$. Using this value together with the known values of $f k_{\mathrm{d}}$ and $k_{\mathrm{p}} c_{\mathrm{M}}$, one can now apply Equation (12) to the data of Figure 3 and thereby procure $k_{\mathrm{t}}{ }^{1,1} \approx 2 \times 10^{8}$ $\mathrm{L} \mathrm{mol}^{-1} \mathrm{~s}^{-1}$ (this value is only an estimate because of the uncertainty introduced by not knowing the mechanism of cross-termination). Both these values are in excellent agreement with those obtained by other methods, ${ }^{[9]}$ although it is stressed that these values pertain to long chains only, not to short chains, meaning that $k_{\mathrm{t}}{ }^{1,1}$ is not the true value of this quantity. ${ }^{[9]}$ We additionally point out that Equation (8) confirms that $\left\langle k_{t}\right\rangle$ is independent of $k_{\operatorname{trX}} c_{X}$ in the termination limit, exactly as seen in Figure 1(b) (values at low $k_{\operatorname{trX}} c_{X}$ ). Summarizing this section, it has firstly illustrated the capacity of Figure 1 and Equation (8) to explain trends in RP data. Second, it has demonstrated how Equation (8) can easily be used to extract accurate quantitative information on CLDT from simple steady-state experiments. Given all this, Equation (12) is recommended as a powerful tool for understanding RP kinetics.

\section{The Transfer Limit}

Making the same clutch of mathematical assumptions as used in deriving Equation (8), except for now considering the transfer limit rather than the termination limit, one can derive ${ }^{[21]}$

$$
\begin{aligned}
& \left\langle k_{\mathrm{t}}\right\rangle(\text { geometric mean })=k_{\mathrm{t}}^{1,1}\left[\Gamma\left(1-\frac{e}{2}\right)\right]^{2}\left(\frac{k_{\mathrm{trX}} c_{\mathrm{X}}}{k_{\mathrm{p}} c_{\mathrm{M}}}\right)^{e} \\
& \left\langle k_{\mathrm{t}}\right\rangle(\text { diffusion mean })=k_{\mathrm{t}}^{1,1} \Gamma(1-e)\left(\frac{k_{\mathrm{trX}} c_{\mathrm{X}}}{k_{\mathrm{p}} c_{\mathrm{M}}}\right)^{e}
\end{aligned}
$$

No closed result is possible with the harmonic mean, however it has been shown numerically to display the same qualitative behavior as Equations (13) and (14). ${ }^{[21]}$ So exactly as with the termination limit, all cross-termination models give the same trends in the transfer limit. Thus one may confidently use the above equations to understand patterns of behavior in transferdominated systems. The first thing one notices is that $\left\langle k_{t}\right\rangle$ is independent of $R_{\text {init }}$ in this limit, as observed in Figure 1(a) (region of low $R_{\text {init }}$ ). The next thing one notices is that $\left\langle k_{\mathrm{t}}\right\rangle$ increases with increasing transfer frequency, completely in accord with Figure 1(b) (region at 
high $\left.k_{\operatorname{trX}} c_{X}\right)$. Further, the more marked is the CLDT (i.e., the higher the value of $e$ ), the stronger this effect. Of course this makes sense physically, but Equations (13) and (14) additionally provide a quantitative footing for analyzing this effect.
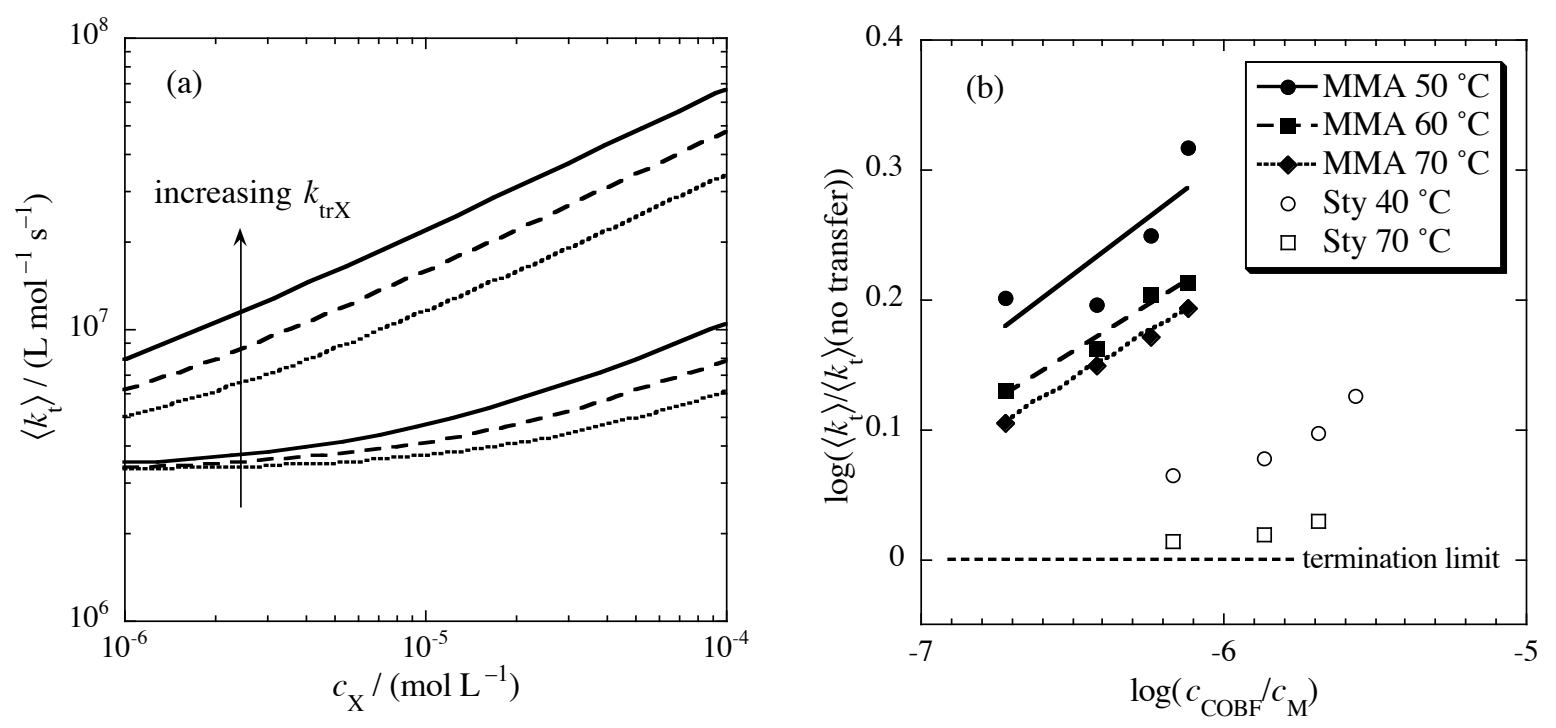

Figure 4. (a) Calculated $\left\langle k_{\mathrm{t}}\right\rangle$ using the parameter values of Figure 1(b). Bottom group of curves: $k_{\mathrm{trX}}=1,2$ and $4 \times 10^{2} \mathrm{~L} \mathrm{~mol}^{-1} \mathrm{~s}^{-1}$; top group: $k_{\mathrm{trX}}=0.5,1$ and $2 \times 10^{4} \mathrm{~L} \mathrm{~mol}^{-1} \mathrm{~s}^{-1}$. (b) Relative $\left\langle k_{t}\right\rangle$ for low-conversion bulk RP of MMA and Sty in the presence of COBF. ${ }^{[22]}$ Linear best fits to each set of MMA data are shown, as is the termination limit value.

All the above may be illustrated by considering data for bulk, low-conversion polymerization of MMA and styrene (Sty) in the presence of the catalytic chain transfer agent known as COBF. ${ }^{[22]}$ To begin with, calculations are presented in Figure 4(a) for variation of $\left\langle k_{\mathrm{t}}\right\rangle$ with $c_{\mathrm{X}}$ for different $k_{\text {trX }}$ (each curve in Figure 4(a) is just a version of Figure 1(b)). All parameter values used in Figure 4(a) have been chosen to reflect those of the experimental results ${ }^{[22]}$ presented in Figure 4(b): relative $\left\langle k_{\mathrm{t}}\right\rangle$ was measured as a function of COBF level for the two monomers at different temperatures. It should be clear why these two figures have been juxtaposed: because the model calculations explain all aspects of the experimental results, most notably: $\left\langle k_{\mathrm{t}}\right\rangle$ is higher for MMA because $k_{\mathrm{trX}}-$ actually, $k_{\operatorname{trX}} / k_{\mathrm{p}}$ is the important parameter - is higher; ${ }^{[22]}\left\langle k_{\mathrm{t}}\right\rangle$ decreases with temperature for both monomers because $k_{\mathrm{trX}} / k_{\mathrm{p}}$ decreases with temperature; ${ }^{[22]}$ the MMA results are steeper because they are in the transfer limit whereas the Sty systems have mixed transfer and termination (see Figure 1(b)), consistent with COBF being a much less efficient CTA for Sty; ${ }^{[22,23]}$ and this is also why the 
Sty results are curved whereas the MMA results are linear (within experimental precision). All these trends defy explanation outside the current framework, and indeed this is the first time they have been explained.

Equations (13) and (14) may also be used for quantitative analysis of data: they dictate that for transfer-dominated systems, i.e., the present MMA data but not the present Sty data, a plot of $\log \left\langle k_{\mathrm{t}}\right\rangle v s . \log c_{\mathrm{X}}$ has slope of $e$, providing all else is held constant, as is the case here. From the linear fits of Figure 4(b) one thus obtains $e=0.18,0.14$ and 0.14 for MMA at 50, 60 and $70{ }^{\circ} \mathrm{C}$ respectively. These values are consistent with those obtained by other means, ${ }^{[9]}$ including the termination-limit data of Figure 3 here. Unfortunately it is not possible to estimate $k_{\mathrm{t}}{ }^{1,1}$ from the intercepts of the linear fits Figure 4(b), because only relative rather than absolute rates were reported. ${ }^{[22]}$

\section{Number-Average Degree of Polymerization}

So far only the effect of CLDT on $\left\langle k_{t}\right\rangle$, and hence, via Equation (1), on rate, has been considered. CLDT also affects molecular weight (MW). Of course MW is important both in its own right and in that it is very commonly measured as part of RP studies. Properly the whole distribution of MWs should be considered, but there is no denying that it is more convenient to deal with a single index of $\mathrm{MW}$; further, quite often a single parameter is adequate as a description of MW. Here we will use number-average degree of polymerization, $D P_{\mathrm{n}}$, which is both commonly employed and is the most intuitive of MW indexes: it is just the arithmetic mean of the number distribution of dead chains. Thus for steady-state polymerizations it may be calculated as the arithmetic mean of $\mathrm{d} c_{\mathrm{D}^{i}} / \mathrm{d} t$ values, as delivered by Equation (4). Before presenting any such results, it is worthwhile contemplating what might be expected. Easiest are transfer-dominated systems, for which $D P_{\mathrm{n}}=\left(k_{\mathrm{p}} c_{\mathrm{M}}\right) /\left(k_{\operatorname{trX}} c_{\mathrm{X}}\right)$. Thus one immediately obtains from Equation (13):

$$
\left\langle k_{\mathrm{t}}\right\rangle(\text { transfer limit })=k_{\mathrm{t}}^{1,1} G_{\text {transfer }}\left(D P_{\mathrm{n}}\right)^{-e}, \text { where } G_{\text {transfer }}=\left[\Gamma\left(1-\frac{e}{2}\right)\right]^{2}
$$

More difficult to show, it turns out that for disproportionation-dominated systems ${ }^{[9,15]}$

$$
\left\langle k_{\mathrm{t}}\right\rangle(\text { disprop. limit })=k_{\mathrm{t}}^{1,1} G_{\text {disprop }}\left(D P_{\mathrm{n}}\right)^{-e}, \text { where } G_{\text {disprop }}=\left[\Gamma\left(\frac{2}{2-e}\right)\right]^{e-2}\left(\frac{2}{2-e}\right)^{e}
$$


Even more remarkable here than the identical scaling behavior - i.e., variation of $\left\langle k_{t}\right\rangle$ with $D P_{\mathrm{n}}$ - is the almost exact quantitative coincidence, e.g. $e=0.20$ gives $G_{\text {transfer }}=1.14$ and $G_{\text {disprop }}=1.13$, while $e=0.50$ gives 1.50 and 1.36 respectively. Where transfer and disproportionation both occur, points are constrained to lie between the two limits of Equations (15) and (16) respectively. Because, as explained, these limits are nearly identical, points in between must be almost exactly described by either of the above equations. This is illustrated in Figure 5, which shows $\left\langle k_{\mathrm{t}}\right\rangle$ as a function of $D P_{\mathrm{n}}$ from calculations in which both transfer and disproportionation are allowed to occur, as well as evaluation of Equations (15) and (16) with the same parameter values.
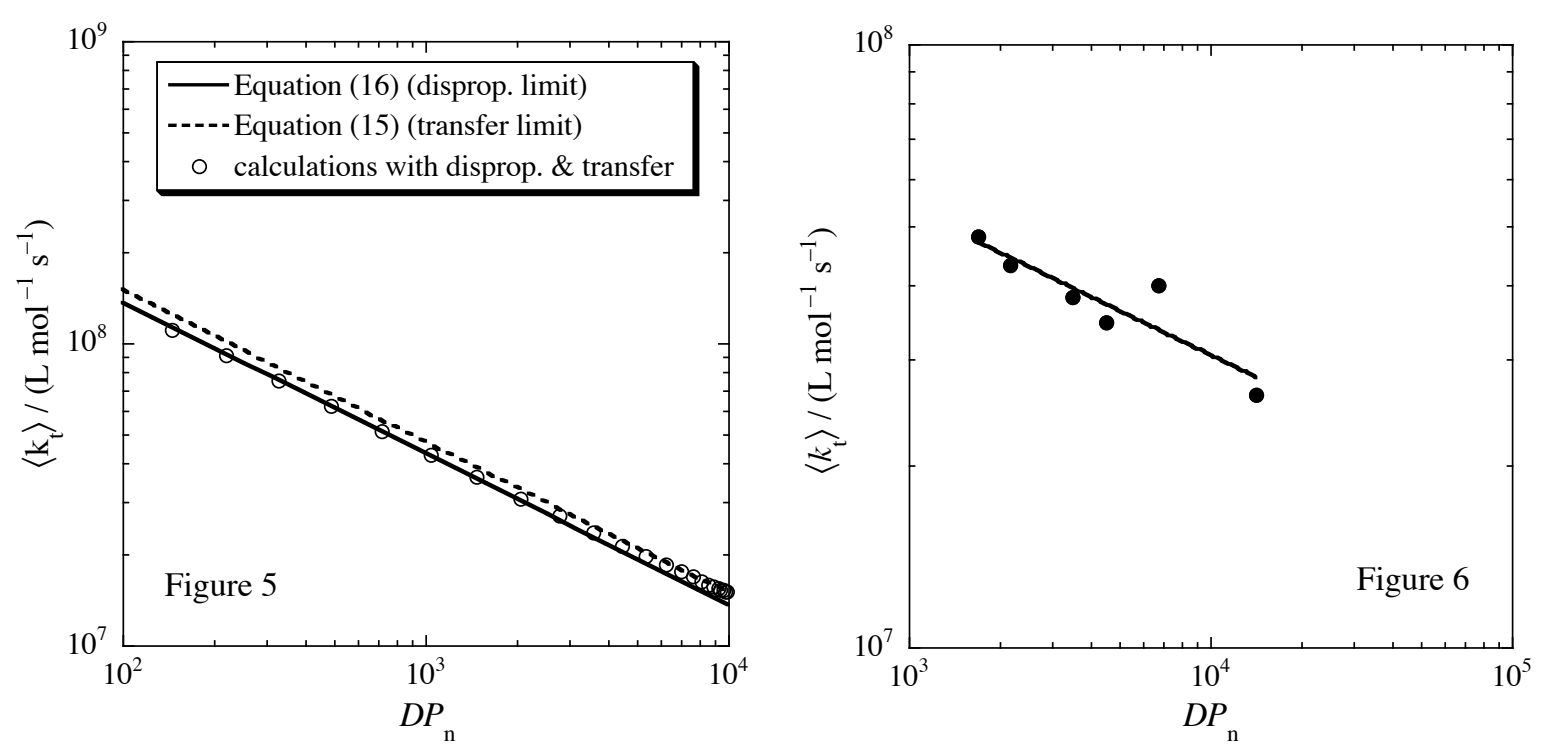

Figure 5 (left). Points: calculations of Figure 1(a), using also $\lambda=1$, presented as $\left\langle k_{\mathrm{t}}\right\rangle v s$. $D P_{\mathrm{n}}$. Lines: evaluations of Equations (15) and (16) using same parameter values as for calculations. Figure 6 (right). Points: variation of $\left\langle k_{\mathrm{t}}\right\rangle$ with $D P_{\mathrm{n}}$ for AIBME-initiated bulk RP of MMA at $40^{\circ} \mathrm{C}^{[20]}$ Line: linear best fit. The $\left\langle k_{\mathrm{t}}\right\rangle$ measurements were made using the "steady-state rate" method of Table 1.

Figure 5 illustrates not just that $\log \left\langle k_{\mathrm{t}}\right\rangle v s . \log D P_{\mathrm{n}}$ is linear regardless of the balance of the competition between termination and transfer, but it also illustrates why this is so. From Equations (15) and (16) one thus has the following simple, powerful, intuitively reasonable and widely applicable relationship: $:^{[9,12,13]}$

$$
\left\langle k_{\mathrm{t}}\right\rangle=k_{\mathrm{t}}^{1,1} G\left(D P_{\mathrm{n}}\right)^{-e}
$$

Figure 6 shows an example of applying this to experimental data: from the slope one obtains 
$e=0.24$, from the intercept $k_{\mathrm{t}}{ }^{1,1} \approx 3 \times 10^{8} \mathrm{~L} \mathrm{~mol}^{-1} \mathrm{~s}^{-1}$ (taking the lazy option of $G \approx 1$ ) or $k_{\mathrm{t}}^{1,1} \approx 2 \times 10^{8} \mathrm{~L} \mathrm{~mol}^{-1} \mathrm{~s}^{-1}$ (the more refined option of using Equation (16) for $G$ ). The accuracy of these values has been established (see above). Note though that Equation (17) can break down, e.g. if $e$ is high or combination is occurring in competition with transfer. ${ }^{[21]}$

\section{Conclusion}

It has been shown that the phenomenon of CLDT results in RP kinetics being writ on a rich, fascinating tableau. Hopefully this work has helped to promote understanding of these complexities. The discussed trends hold for RP in general, the presented equations for steady state only. Using the latter it has been shown that simple steady-state experiments can yield good information on CLDT, although there is no disputing that single-pulse PLP remains the method of choice for such studies ${ }^{[10,11]}$ (see Table 1). In particular the transfer limit is recommended as an important but little realized phenomenon: it can have the guise of 'classical' kinetics (e.g., $\left\langle k_{\mathrm{t}}\right\rangle$ invariant with $R_{\text {init }}$ ) where actually CLDT is occurring.

[1] O. F. Olaj, I. Bitai, F. Hinkelmann, Makromol. Chem. 1987, 188, 1689.

[2] M. Buback, R. G. Gilbert, R. A. Hutchinson, B. Klumperman, F.-D. Kuchta, B. G. Manders, K. F. O'Driscoll, G. T. Russell, J. Schweer, Macromol. Chem. Phys. 1995, 196, 3267.

[3] A. M. van Herk, Macromol. Theory Simul. 2000, 9, 433.

[4] S. Beuermann, M. Buback, Prog. Polym. Sci. 2002, 27, 191.

[5] C. Barner-Kowollik, M. Buback, M. Egorov, T. Fukuda, A. Goto, O. F. Olaj, G. T. Russell, P. Vana, B. Yamada, P. B. Zetterlund, Prog. Polym. Sci. 2005, 30, 605.

[6] M. Buback, M. Egorov, R. G. Gilbert, V. Kaminsky, O. F. Olaj, G. T. Russell, P. Vana, G. Zifferer, Macromol. Chem. Phys. 2002, 203, 2570.

[7] M. Buback, H. Hippler, J. Schweer, H.-P. Vögele, Makromol. Chem., Rapid Commun. 1986, 7, 261.

[8] J. P. A. Heuts, G. T. Russell, Eur. Polym. J. 2006, 42, 3.

[9] G. B. Smith, G. T. Russell, J. P. A. Heuts, Macromol. Theory Simul. 2003, 12, 299.

[10] M. Buback, M. Egorov, T. Junkers, E. Panchenko, Macromol. Rapid Commun. 2004, $25,1004$.

[11] M. Buback, E. Müller, G. T. Russell, J. Phys. Chem. A 2006, 110, 3222.

[12] O. F. Olaj, G. Zifferer, Makromol. Chem., Macromol. Symp. 1987, 10/11, 165.

[13] O. F. Olaj, G. Zifferer, Macromolecules 1987, 20, 850.

[14] G. T. Russell, Aust. J. Chem. 2002, 55, 399.

[15] O. F. Olaj, G. Zifferer, G. Gleixner, Makromol. Chem., Rapid Commun. 1985, 6, 773.

[16] O. F. Olaj, G. Zifferer, G. Gleixner, Makromol. Chem. 1986, 187, 977.

[17] G. T. Russell, Macromol. Theory Simul. 1994, 3, 439.

[18] G. T. Russell, Macromol. Theory Simul. 1995, 4, 519.

[19] G. B. Smith, J. P. A. Heuts, G. T. Russell, Macromol. Symp. 2005, 226, 133.

[20] M. Stickler, Makromol. Chem. 1986, 187, 1765.

[21] G. B. Smith, G. T. Russell, results to be published.

[22] D. Kukulj, T. P. Davis, Macromol. Chem. Phys. 1998, 199, 1697.

[23] J. P. A. Heuts, G. E. Roberts, J. D. Biasutti, Aust. J. Chem. 2002, 55, 381. 